\title{
Back to the future? How Chinese-English bilinguals switch between front and back orientation for time
}

Abbreviated title: Cross-language interference on time conceptualisation

Yang $\mathrm{Li}^{1}$, Aina Casaponsa ${ }^{2}$, Yan Jing $\mathrm{Wu}^{3}$, and Guillaume Thierry ${ }^{1}$

1. School of psychology, Bangor University, Bangor, Wales, UK

2. Department of Linguistics and English Language, Lancaster University, Lancaster, UK

3. Faculty of Foreign Languages, Ningbo University, Ningbo, China

\begin{abstract}
The ability to conceive time is a corner stone of human cognition. It is unknown, however, whether time conceptualisation differs depending on language of operation in bilinguals. Whilst both Chinese and English cultures associate the future with the front space, some temporal expressions of Chinese involve a configuration reversal due to historic reasons. For instance, Chinese refers to the day after tomorrow using the spatiotemporal metaphor hou-tian - 'back-day' and to the day before yesterday using qian-tian - 'front-day'. Here, we show that native metaphors interfere with time conceptualisation when bilinguals operate in the second language. We asked Chinese-English bilinguals to indicate whether an auditory stimulus depicted a day of the week either one or two days away from the present day, irrespective of whether it referred to the past or the future, and ignoring whether it was presented through loudspeakers situated in the back or the front space. Stimulus configurations incongruent with spatiotemporal metaphors of Chinese (e.g., "Friday" presented in the front of the participant during a session held on a Wednesday) were conceptually more challenging than congruent configurations (e.g., the same stimulus presented in their back), as indexed by $\mathbf{N} 400$ modulations of event-related brain potentials. The same pattern obtained for days or years as stimuli, but surprisingly, it was found only when participants operated in English, not in Chinese. We contend that the task was easier and less prone to induce cross-language activation when conducted in the native language. We thus show that, when they operate in the second language, bilinguals unconsciously retrieve irrelevant native language representations that shape time conceptualisation in real time.
\end{abstract}




\section{Introduction}

27 Conceptualising the passing of time is a core aptitude of the human mind. One of the most common ways to represent time, an abstract concept, is to use space, a concrete concept. However, linguistic metaphors from different languages use spatial axes in different ways.

30 For instance, spatiotemporal metaphors of Chinese frequently refer to the sagittal (front-back) and vertical (up-down) axes to represent time (e.g., Boroditsky, 2001; Boroditsky, Fuhrman, and McCormick, 2011; Lai and Boroditsky, 2013). Western languages, in contrast, tend to rely more exclusively on the sagittal axis.

34 Languages even differ in terms of orientation along the same axis. Whereas Aymara, like Moroccan, associates the past with the front space (nayra) and the future with the back space (qhipa), the majority of languages place the future in front and the past in the back (Núñez and Sweetser, 2006; see also, de la Fuente, Santiago, Román, Dumitrache, and Casasanto, 2014). Variations even exist within languages, as is the case in Chinese, which conforms to a future-in-front convention (e.g., qian-tu - 'future prospects' literally translates into "frontpath") but features exceptions with a reverse orientation along the same axis (e.g., hou-tian-

41 'the day after tomorrow', which literally translates as "back-day", Table 1).

Table 1. Spatiotemporal metaphors of Mandarin Chinese conflicting with the future-in-front convention

\begin{tabular}{lllll} 
Chinese & Pin Yin & English translation & Time & Literal translation \\
\hline 后天 & hou-tian & the day after tomorrow & future & 'back day' \\
前天 & qian-tian & the day before yesterday & past & 'front day' \\
后年 & hou-nian & the year after next & future & 'back year' \\
前年 & qian-nian & the year before last & past & 'front year' \\
\hline
\end{tabular}

One fundamental question, however, is whether such linguistic differences are mirrored by differences at a conceptual level, that is, the question at the centre of the linguistic relativity debate (Lupyan, 2012; Slobin, 1996; Thierry, 2016; Whorf, 1956). In the domain of time representation, Boroditsky (2001) reported that native speakers of Chinese solved temporal problems (e.g., Is "March comes earlier than April" correct?) faster after viewing pictures of vertically arranged objects than horizontally arranged ones. In contrast, English native speakers verified temporal statements faster after presentation of horizontal layout than vertical ones. Boroditsky thus argued that native speakers of 
Chinese predominantly conceptualise time along the vertical axis, whereas English natives predominantly embody time along the horizontal axis. However, using the same paradigm as Boroditsky (2001), Chen (2007) failed to find significant reaction time differences between horizontal and vertical spatial priming in Chinese native speakers or English native speakers. In addition, in a corpus analysis, Chen (2007) observed that Chinese native speakers more frequently used horizontal spatial metaphors than vertical ones when expressing time (with the notable exception of temporal expressions containing "week"). This led Chen (2007) to argue that Chinese speakers, like English speakers, predominantly conceptualize time horizontally, despite the existence of vertically oriented spatiotemporal metaphors in Chinese. In addition, also against observations made by Boroditsky (2001), January and Kako (2007) and Tse and Altarriba (2008) showed that English native speakers take less time to respond to temporal sentences following a vertical than a horizontal prime. Therefore, data from behavioural studies have so far failed to reach a consensus on spatiotemporal interactions between language-specific metaphors and time conceptualisation.

In order to assess how specific linguistic expressions such as spatiotemporal metaphors influence how speakers of different languages conceive time, we need an implicit, automatic, and unconscious index of conceptual processing that is resilient to strategic effects and does not rely on verbalisation (Thierry, 2016). A well-established such index is the N400 peak of event-related brain potentials (Kutas and Hillyard, 1980, 1984; Kutas, Lindamood, and Hillyard, 1984). Here, we set out to test whether spatiotemporal metaphors specific to Chinese that conflict with the future-in-front convention ${ }^{1}$ selectively affect time conceptualisation in fluent Chinese-English bilinguals operating in English or Chinese. It is well-established that lexical access in bilinguals is largely language non-selective and that the bilingual lexicon is highly integrated rather than fragmented by language (See the bilingual interactive activation model, van Heuven, Dijkstra, and Grainger, 1998;

\footnotetext{
${ }^{1}$ We chose the sagittal (front-back) axis for three reasons: (i) The sagittal axis is the most frequently used; (ii) It is common to Mandarin Chinese and English, which is critical because we tested Chinese-English bilinguals in the UK; (iii) Exceptional violations of the future-infront convention only occur in Chinese.
} 
index of cross-language activation established that there are automatic competition effects within and across languages at the lexical level, even when bilinguals operate in a monolingual language context (Thierry and $W u, 2004,2007$; Wu and Thierry, 2010, 2012; Hoshino and Thierry, 2012; Wen, Filik, and van Heuven, 2018; Meade et al., 2017; Lee, Meade, Midgley, Holcomb \& Emmorey, 2019). Therefore, we predicted that Chinese-English bilinguals operating in English could suffer interference from spatiotemporal metaphors specific to Chinese.

We engineered a conflict between metaphor orientation and stimulus presentation along the front-back axis in the space around the participant. To our knowledge, no previous study has physically presented a stimulus in the back space surrounding participants, since all previous studies involved stimuli presented in the visual domain. In Experiment 1, we used days of the week as stimuli. For instance, when a participant was tested on a Wednesday, we presented the auditory stimulus 'Friday' through loudspeakers situated in the front of the participant, potentially clashing with the corresponding spatiotemporal metaphor of Chinese as compared to the same stimulus presented in their back, since the Chinese expression for 'the day after tomorrow" literally translates as "back-day" in English. We asked participants to make interval judgements ('Is the date you hear one or two days away from today?'). Critically, sound origin in space was irrelevant as was the future or past reference afforded by the stimuli, and spatiotemporal metaphors were never presented or mentioned.

We expected that Chinese-English bilinguals would experience interference from conflicting metaphors of Chinese in the case of 2-day gaps, but not in the case of 1-day gaps since mingtian - 'tomorrow' and zuo-tian - 'yesterday' are not spatiotemporal metaphors in Chinese

99 (Table 2).

Table 2. Temporal expressions of Mandarin Chinese neutral vis-à-vis the future-in-front convention

\begin{tabular}{lllll} 
Chinese & Pin Yin & English translation & Relative time & Literal translation \\
\hline 明天 & ming-tian & tomorrow & future & 'bright day' \\
昨天 & zuo-tian & yesterday & past & 'yesterday' \\
明年 & ming-nian & next year & future & 'bright year' \\
去年 & qu-nian & last year & past & 'gone year' \\
\hline
\end{tabular}


100 In Experiment 2, conducted in late 2017 in the same session as Experiment 1, participants

101 made interval judgements about years instead of days. Our predictions were the same as for

102 Experiment 1 (Fig. 1).

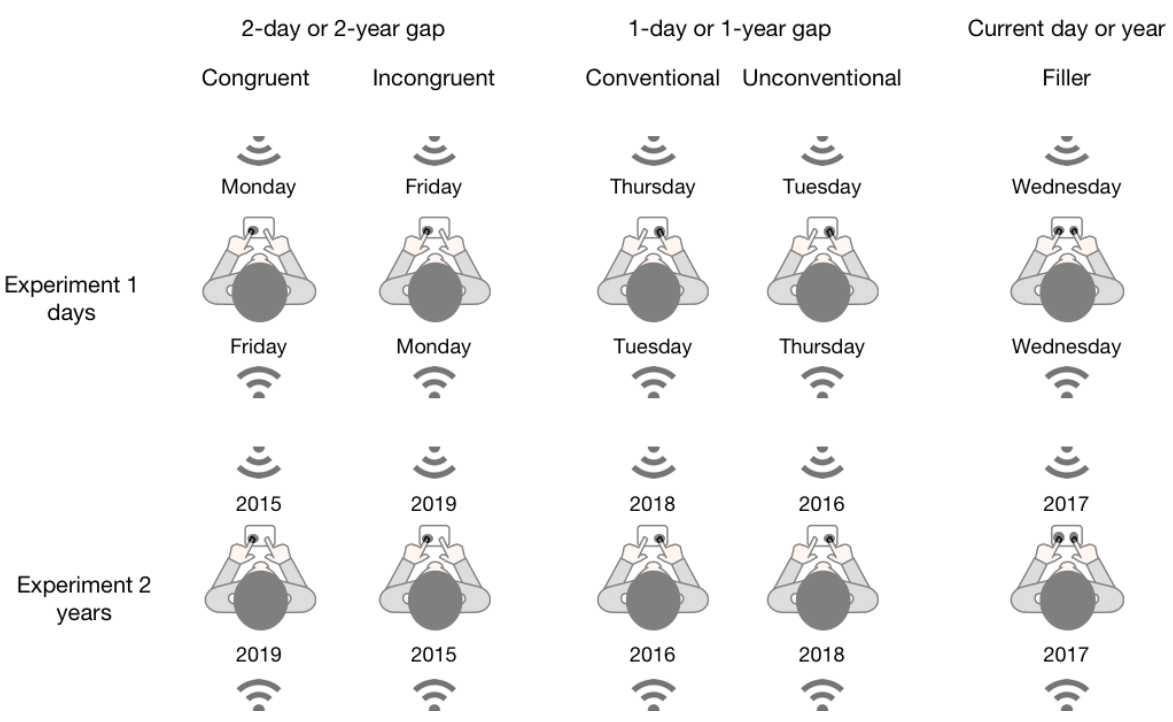

Figure 1. Experimental design. In experiment 1, participants heard days of the week presented through loudspeakers set in front of them and in their back. Stimuli depended on the day of testing (e.g., if the current day was Wednesday, stimuli were Monday, Tuesday, Wednesday, Thursday, and Friday in English and xing-qi yi, xing-qi er, xing-qi san, xing-qi si, and xing-qi wu in Chinese). Participants were instructed to press one button for stimuli one day away (in the future or the past) and the other button for stimuli two days away from the day of testing. For the current day, they had to press both buttons simultaneously (filler trial). In experiment 2 , participants heard year labels: twenty-fifteen, twenty-sixteen, twenty-seventeen, twenty-eighteen, and twentynineteen (and er-ling yi-wu, er-ling yi-liu, er-ling yi-qi, er-ling yi-ba, er-ling yi-jiu in Chinese). Instructions were the same as in Experiment 1 but response was based on temporal distance in years, 2017 being the year of testing. Congruency is defined based on alignment between sound origin (front / back), temporal reference (future /past), and spatiotemporal metaphors of Mandarin Chinese.

103 Overall, we predicted that incongruent stimulus configurations involving 2-day or 2-year

104 gaps presented from a location incompatible with the orientation embedded in native

105 spatiotemporal metaphors of Chinese would differentially increase the amplitude of the N400

106 as compared to congruent configurations. In the case of 1-day or 1-year gaps, configurations

107 violating the future-in-front convention were not expected to elicit semantic interference

108 since no relevant spatial information was available, either in Chinese or in English. 
111 Participants

112 Twenty-four Chinese-English bilingual participants and 21 native speakers of English

113 participated in this study. All participant took part in both Experiment 1 and Experiment 2.

114 Data from 5 bilingual participants and 4 native speakers of English were discarded due to

115 poor electrophysiological recording quality, excessively high impedances, excessive blinking,

116 or insufficient number of trials per condition. All Chinese participants reported their

117 International English Language Test System (IELTS) score (Mean $=6.3 / 9, \mathrm{SD}=0.4)$ and

118 were resident in the UK at the time of testing. Bilingual participants self-reported their

119 proficiency in both English and Mandarin Chinese (Fig. 2) and their language background is 120 summarised in Table 3.

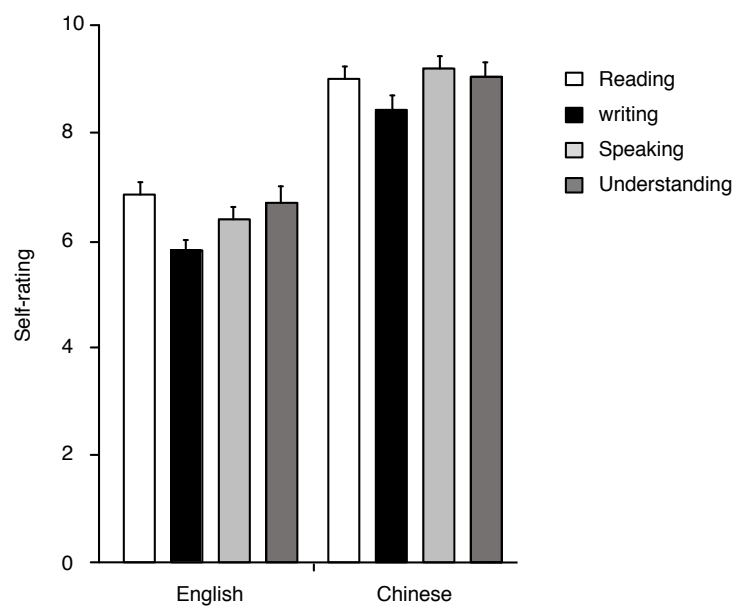

Figure 2. Chinese-English bilingual participants' self-estimation of their English and Chinese level (10 pointscale). Error bar represents stand error.

122 All participants had normal or corrected-to-normal vision and self-reported normal audition.

123 Participants either received $£ 15$ or course credits for their participation in the study that was approved by the ethics committee of the School of Psychology at Bangor University. We aimed at collecting more than 16 participants in each of the experimental groups in order to yield suitable statistical power for this experiment based on previous studies targeting similar effects in ERPs and spanning 9 years of research (e.g., Thierry and Wu, 2004, 2007). We thus collected 21 participants in the native English group based on an average data attrition rate of $\sim 10 \%$, and 24 bilingual participants, since session duration was twice as long thus increasing data loss risks proportionally. 
Table 3. Chinese-English bilingual participants' language background

132

133

134

135

136

137

138

139

140

141

142

143

144

145

146

\begin{tabular}{lll} 
Measure & Mean & SD \\
\hline Age of L2 acquisition & 9.42 & 2.36 \\
Length of L2 learning (years) & 14.26 & 3.57 \\
Daily Chinese usage (\%) & 67 & 16.7 \\
Daily English usage (\%) & 33 & 14.1 \\
\hline
\end{tabular}

\section{Materials}

Stimuli consisted of digital audio files of days of the week and year numbers in Mandarin Chinese and English. All stimuli were recorded once in English by a native speaker of English and once in Chinese by a native speaker of Chinese. A cross-splicing procedure (using Adobe Audition ${ }^{\mathrm{TM}}$ ) was employed to ensure that participants could not guess the particular day or year stimulus presented in each trial on the basis of stimulus beginning alone $^{2}$. Cross-splicing offered a good baseline and optimal accuracy in marking the onset of the critical information in the sound stream (Fig. 3).

A

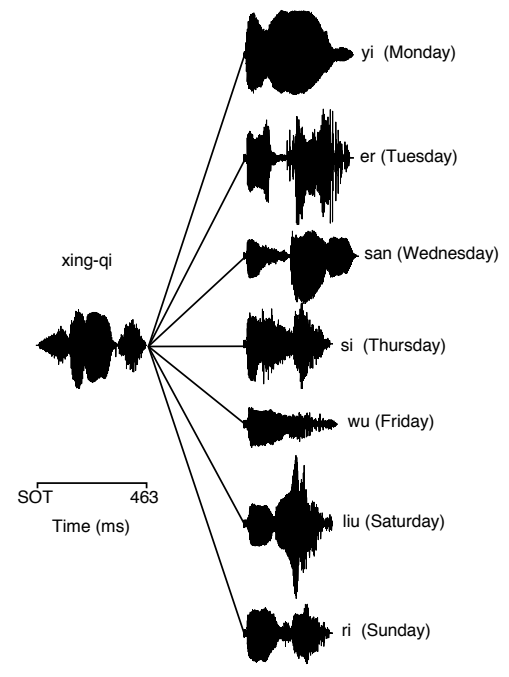

B

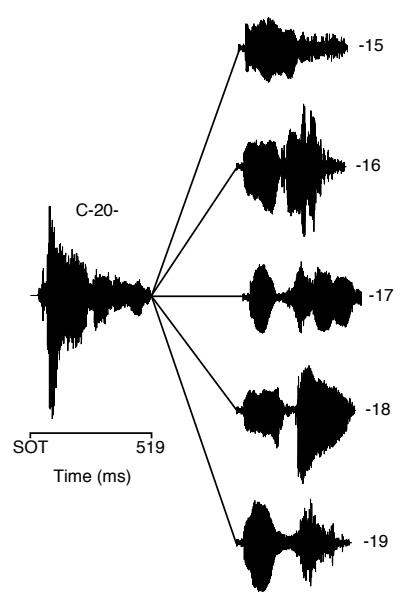

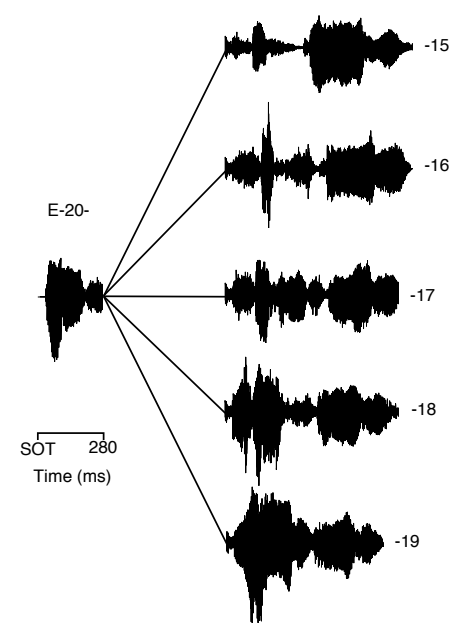

Figure 3. Cross-splicing procedure and stimuli presented. (A) Experiment 1 (days). (B) Experiment 2 (years).

\footnotetext{
${ }^{2}$ Note that for year stimuli in Chinese, we elected not to cross-splice between the decade digit ( $y i-$ 'one' in Chinese) and the final digit $(5,6,7,8$, or 9) because of co-articulation in the case of $y i-w u$ - 'fifteen', which would have created an artefact for that sound file. On average the duration of $y i$ was $250 \mathrm{~ms}$ (range $230-272 \mathrm{~ms}$ ), and thus RTs were artificially extended by the same duration in the corresponding condition.
} 
147 In Experiment 1, stimuli consisted of the names for the 7 days of the week. For any

148 participant, only 5 days of the week were presented in order to cover a time interval of two

149 days before to two days after the day of testing. Average stimulus duration was $900 \pm 75 \mathrm{~ms}$

150 for days in Chinese and $845 \pm 66 \mathrm{~ms}$ for days in English day. Average auditory stimulus

151 intensity was $48 \mathrm{~dB}$ (range $46-55 \mathrm{~dB}$ ).

152 In experiment 2, stimuli were 4-digit numbers referring to 5 years surrounding the year of testing (2017), i.e., 2015, 2016, 2017, 2018, and 2019. Average stimulus duration was 1076

$154 \pm 23 \mathrm{~ms}$ for years in Chinese and $1163 \pm 66 \mathrm{~ms}$ for years in English day. Average auditory 155 stimulus intensity was $48 \mathrm{~dB}$ (range $47-52 \mathrm{~dB}$ ).

\section{Procedure}

157 Participants first completed a language background and reading habits questionnaire whilst

158 being fitted with the cap for electrophysiological recording. They were seated in the centre of

159 a sound-attenuated testing booth, with two speakers located in the front and two speakers

160 located behind them, set at a distance of between 1.4-1.6 meters from their ears. A 19-inch

161 CRT monitor was placed $100 \mathrm{~cm}$ in front of their eyes and displayed a black fixation cross on

162 a white background throughout the recording session. In experiment 1, participants were

163 asked to judge whether each stimulus referring to a day of the week corresponded to a period

164 of time situated one or two days away from the current day. In experiment 2, participants

165 made the same judgements for stimuli referring to years. Responses were given by pressing

166 designated left and right buttons on a response box. Response sides were counterbalanced

167 between participants. Half of the stimuli were presented through the speakers located in front

168 of the participant's chair, and the other half were presented in their back. When participants

169 heard the current day or the current year, they were instructed to press both left and right

170 buttons simultaneously. They heard 30 pseudo-randomly intermixed iterations of each

171 individual stimulus condition. Apart from present day (one fifth of trials), half of the stimuli

172 were one day away from the time of testing and the other half were two days away from the

173 time of testing. Similarly, half of the stimuli referred to the future and half to the past, making

174 a total of 300 trials per block in each experiment. Control native speakers of English

175 performed the task in English only (600 trials in total) and Chinese-English participants

176 performed the task once in English and once in Chinese (1200 trials in total) with order

177 counterbalanced between languages (all bilingual participants completed Experiment 1 or 
179 language order was counterbalanced between them). Every individual trial started with a

180 pink fixation cross displayed in the centre of the screen for $300 \mathrm{~ms}$. The fixation then turned

181 to black after a pseudorandom inter-stimulus interval of 300-500 ms. The target auditory

182 stimulus was then presented through loudspeakers either to the front or the back of the

183 participant's chair whilst the black fixation stayed on the screen until participant's response

184 with a maximum duration of three seconds from the onset of the sound stimulus. Participant's

185 response immediately triggered a $200 \mathrm{~ms}$ inter-trial interval before the next pink fixation.

186 Every 7 trials, the pink fixation lasted for four seconds, during which participants were

187 encouraged to blink if they needed to, in order to minimise the occurrence of eye blink

188 artefacts during the interval of time between auditory stimulation and response.

\section{ERP recording and processing}

190 Electrophysiological data were recorded at a rate of $1 \mathrm{kHz}$ from $64 \mathrm{Ag} / \mathrm{AgCl}$ electrodes according to the extended 10-20 convention and referenced to electrode $\mathrm{Cz}$. Impedances were kept below $5 \mathrm{k} \Omega$. The electroencephalogram (EEG) was filtered using an online bandpass filter $(0.05-200 \mathrm{~Hz})$, and offline using a low-pass, zero phase-shift digital filter $(0.1 \mathrm{~Hz}, 24$ $\mathrm{dB} /$ oct-20 Hz, $28 \mathrm{~dB} /$ oct). Eye-blink artefacts were first manually removed through visual inspection of the data and the remaining artefacts were then mathematically corrected using the procedure advocated by Gratton, Coles and Donchin (1983). Epochs ranging from -200 to $1200 \mathrm{~ms}$ after stimulus onset were extracted from continuous EEG recordings. Epochs with activity exceeding $\pm 100 \mu \mathrm{V}$ at any electrode site, except the vertical electroocculogram channels, were discarded. Baseline correction was performed in reference to pre-stimulus activity, and individual averages were digitally re-referenced to the global average reference.

\section{Behavioural data analysis}

202 Stimulus onsets were corrected to the onset of the critical information in the sound stream

203 (Fig. 3). Reaction times (RTs) below $200 \mathrm{~ms}$ were removed from the analysis (0.05\%). Trials 204 with RTs that deviated 2.5 interquartile range below the $1^{\text {st }}$ and above the $3^{\text {rd }}$ quartile of each participant in each intra-subject variable were considered outliers and discarded from data analyses (1.49\%). Accuracy data and RTs of correct answers were then analysed with logit and linear mixed-effect models respectively [lme4 (Bates, Maechler, and Dai, 2008) package in $\mathrm{R}$ ( $\mathrm{R}$ core Team, 2012)]. Collinearity was not an issue in the models: variance inflation factor (VIF) ranged from 1 to 1.5. All models included random intercepts for subjects and 
items and maximal random slopes for each within-subjects and within-items predictor

211 respectively. Following Barr et al. (2013) and Barr (2013) when models with maximal

212 random structure failed to converge, maximal within-items and within-subject interactions for

213 random slopes were used. All fixed effects were contrast coded before analyses using sum

214 coding so that each model's intercept represented the mean value of each predictor.

215 Significance $P$-values and Type III $F$-statistics for main effects and interactions for

216 continuous variables (RTs) were calculated using Satterthwaite approximations to

217 denominator degrees of freedom as implemented in the LmerTest (Kuznetsova, Brockhoff,

218 and Christensen, 2017) package, and planned comparisons and $\beta$ estimates were calculated

219 using difflemeans and lsmeans as implemented in the lmerTest package. Binary outcomes

220 (accuracy data) were analysed using logit mixed-effects models (Jaeger, 2008). Type III

221 Wald $\chi^{2}$-statistics, $P$-values, planned comparisons and $\beta$ estimates for main effects and

222 interactions were calculated using car (Fox and Weisberg, 2014) and incorporated lsmeans

223 packages (Lenth, 2016).

\section{EEG data analysis}

225 ERP amplitudes were measured at 6 centroparietal electrodes $(\mathrm{C} 1, \mathrm{Cz}, \mathrm{C} 2, \mathrm{CP} 1, \mathrm{CPz}$, and

226 CP2) where the N400 is usually maximal (Kutas and Hillyard, 1980, 1984; Kutas et al.,

227 1984). In experiment 1, for the English day block, mean N400 amplitude were computed

228 between $350-500 \mathrm{~ms}$, determined predictively based on previous literature (Kutas and

229 Hillyard, 1980; 1984; Kutas et al., 1984). For the Chinese Day block, the N400 window was

230 813-963 ms (since xing-qi lasted 463 ms, Fig. 3). In experiment 2, for the English year block,

231 the predicted time-window of the N400 was 630-780 ms after stimulus onset, given that the

232 'twenty-' portion of the auditory stream lasted $280 \mathrm{~ms}$ (Fig. 3). In the Chinese year block, the

233 N400 time window was 869-1019 ms (since er-ling lasted for 519 ms).

\section{Results}

235 To analyse our results, we proceeded in four steps. First, we analysed behavioural measures

236 and ERP results from Experiment 1 (days), starting with 2-day gaps, where spatiotemporal 
metaphor effects were anticipated. We then analysed data for the 1-day gaps where only

238 effects of conventionality could be expected. Third, we analysed data collected in Experiment

2392 (years), to establish whether the pattern of results obtained for days would also obtain for

240 years (replication). Starting with 2-year gaps, we tested for spatiotemporal metaphor

241 congruency and then for conventionality effects in the case of 1-year gaps. Reaction times,

242 accuracy data, and ERP's time-windows were corrected to the onset of the critical

243 information in the sound stream.

\section{Chinese spatiotemporal metaphors for days affect time conceptualisation}

245 In experiment 1, we tested whether a change of language would affect congruency between

246 spatiotemporal metaphors of Chinese and spatiotemporal configuration of the stimuli in

247 Chinese-English bilinguals in the case of two-day intervals. Accuracy was at ceiling in the

248 interval calculation task whether bilinguals heard day stimuli in Chinese or in English (Fig.

249 4A). We found no significant main effect of language (English, Chinese; $\chi^{2}{ }_{1}=\mathbf{2 . 0 6}, \boldsymbol{P}=\mathbf{0 . 1 5}$ )

250 or congruency (congruent, incongruent; $\chi^{2}{ }_{1}=\mathbf{0 . 5 8}, \boldsymbol{P}=\mathbf{0 . 4 5}$ ) on accuracy and no interaction

$251 \quad\left(\chi^{2}{ }_{1}=\mathbf{0 . 1}, \boldsymbol{P}=\mathbf{0 . 7 6}\right)$. As for Reaction Times (RTs), we found a main effect of language ( $F$

$252(1,19.53)=24.66, P<0.001)$ so that bilingual participants were slower responding to English

$253(\beta=1057, S E=54)$ than Chinese stimuli $(\beta=861, S E=37)$. There was no significant main

254 effect of congruency $(F(1,21.01)=1.38, P=0.25)$ and no interaction $(F(1,21.6)=0.49$,

$255 P=\mathbf{0 . 4 9})$.

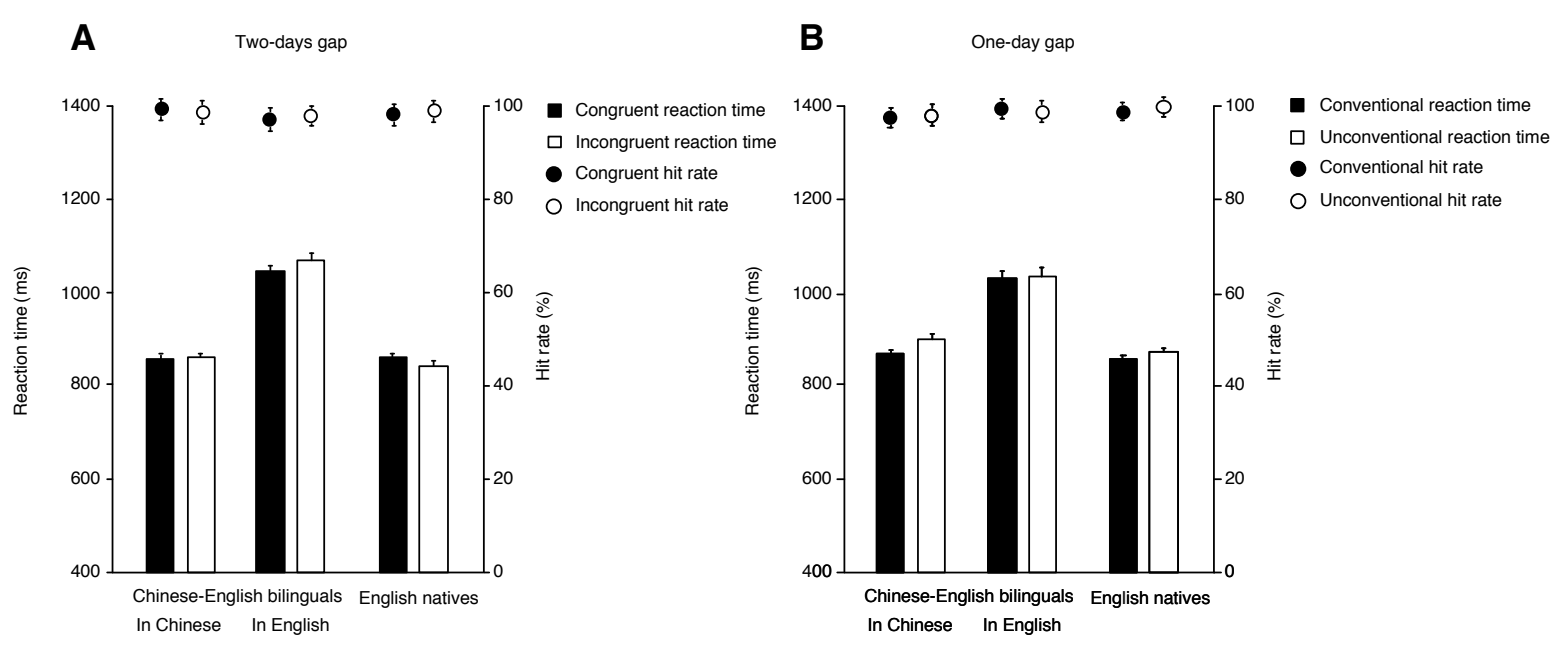

Figure 4. Behavioural results. (A) Two-days gap. (B) One-day gap. Bars represent reaction times and bullets represent accuracy. Error bars depict s.e.m. 
256 We then analysed mean N400 amplitudes in the same Chinese-English bilinguals to

257 determine whether spatiotemporal metaphors interfered with time conceptualisation during

258 the task. A repeated measure ANOVA with language (Chinese, English) and congruency

259 (congruent, incongruent) as within-subject factors revealed a significant effect of congruency

$260 \quad\left(F(1,18)=21.83, P<0.001, \eta_{p}^{2}=0.55\right)$. The effect of language was marginally significant $(F$

$\left.261(1,18)=4.14, P=0.06, \eta_{p}^{2}=0.2\right)$ and the interaction between congruency and language was

262 also significant $\left(F(1,18)=7.06, P=0.02, \eta_{p}^{2}=0.28\right)$. Planned comparisons showed that

263 incongruent stimulus configurations elicited significantly more negative N400 amplitudes

264 than congruent ones when bilingual participants operated in English $(t(18)=4.66, P<0.001$;

265 Fig. 5). No such effect was found when participants responded to Chinese stimuli $(t(18)=-$

$2660.53, P=0.3)$.

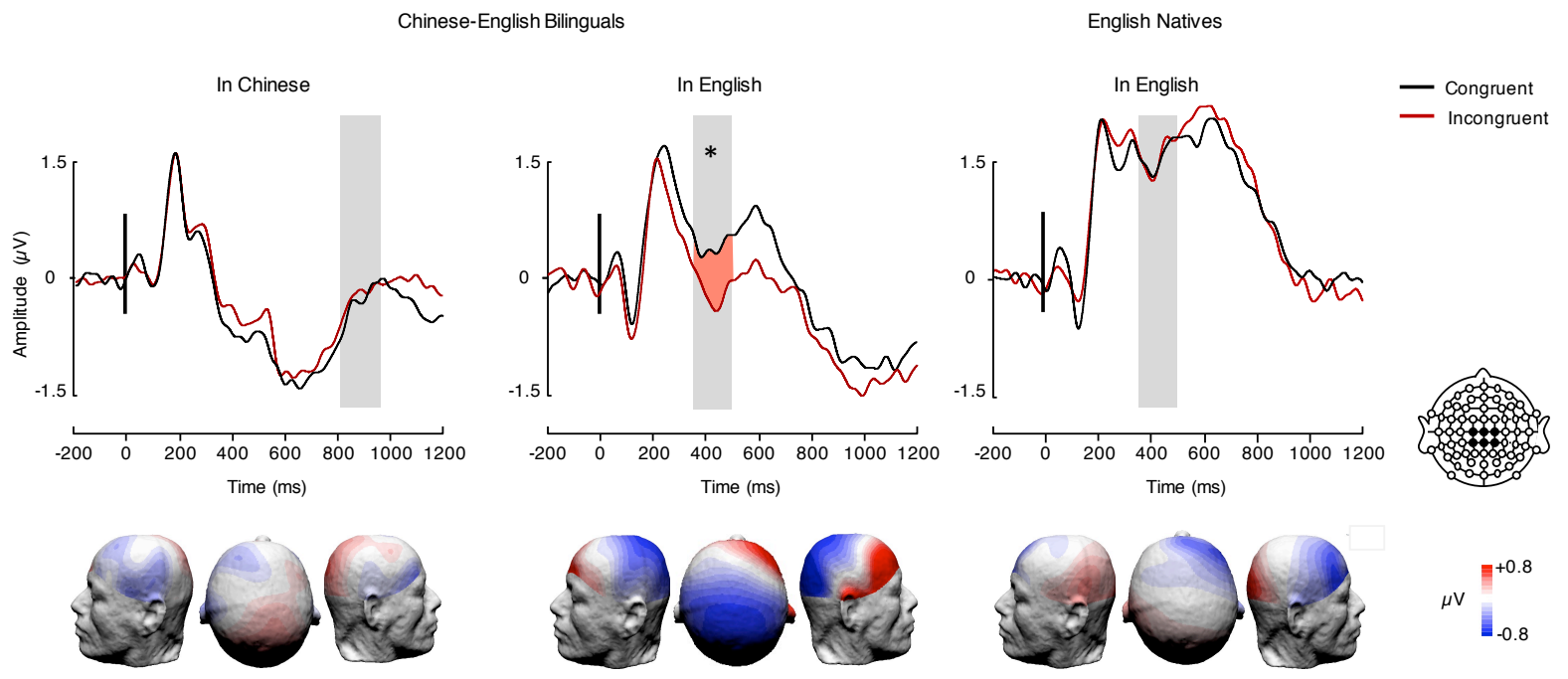

Figure 5. Event-related brain potentials elicited in experiment 1 (days). ERPs depict the linear derivation of 6 electrodes (C1, Cz, C2, CP1, CPz, CP2). Topographical maps show ERP activity across the 64-channel array in the following predictively determined time-windows. N400 amplitudes were computed between 350-500 ms based on previous literature, from the onset of the unique sound streams, irrespective of language or stimulus. In the case of Chinese stimuli, the interval of N400 amplitude extraction was 813-963 ms (since xing-qi - 'week' lasted $463 \mathrm{~ms}$, see Methods) and in the case of English stimuli, the interval of N400 extraction was 350-500 ms, since day stimuli differed from one another from their onset. Topographies depict differences between incongruent and congruent conditions in all cases.

267 In order to further investigate the congruency effect found in bilinguals operating in English, we compared their results with that of English native participants. Accuracy was at ceiling in English native controls. No significant main effect of congruency (congruent, incongruent; $\chi^{2}{ }_{1}=\mathbf{0 . 6 1}, \boldsymbol{P}=\mathbf{0 . 4 4}$ ) or group (English, Chinese-English bilingual; $\chi^{2}{ }_{1}=1.71, P=0.19$ ) was

271 found on accuracy and there was no interaction $\left(\chi^{2}{ }_{1}=\mathbf{0 . 0 1}, \boldsymbol{P}=\mathbf{0 . 9 2}\right.$; Fig. 4A). Regarding 
RTs, Chinese-English bilinguals operating in English were significantly slower $(\beta=1056, S E$ $=48)$ than their English native peers $(\beta=855, S E=50)$, as reflected by a significant main effect of group $(F(1,34.21)=8.45, P<0.001)$. There was no significant main effect of congruency $(F(1,8.06)=3.06, P=0.12)$ and no interaction $(F(1,11.63)=0.05, P=$ 0.83).

A between-subjects repeated measures ANOVA, with congruency as within-subject factor and group (English, Chinese-English bilingual) as between-subject factor conducted on N400 mean amplitude revealed a significant main effect of group $\left(F(1,34)=7.95, P=0.01, \eta^{2}=\right.$ $0.19)$ and a significant effect of congruency $\left(F(1,34)=5.54, P=0.02, \eta_{p}^{2}=0.14\right)$. The interaction was also significant $\left(F(1,34)=5.99, P=0.02, \eta^{2}=0.15\right)$. Planned comparisons showed that incongruent stimulus configurations elicited more negative N400 amplitudes than congruent configurations in bilingual participants $(t(18)=4.66, P<0.001$; Fig. 5), but not in their English peers $(t(16)=-0.05, P=0.48)$.

\section{Conventionality effects for one-day gaps affect behaviour but not ERP amplitudes}

We first tested for effects of conventionality in Chinese-English bilinguals' mind. With regard to accuracy, we found no significant main effect of language (Chinese, English; $\chi^{2} 1$ $<0.01, P=0.97$ ) or conventionality (conventional, unconventional; $\chi^{2}{ }_{1}=0.1, P=0.75$ ). However, there was a significant interaction between language and conventionality $\left(\chi^{2}{ }_{1}=\right.$ 3.88, $P=0.05)$. However, post hoc comparisons failed to show effects of conventionality in either Chinese $(\beta=-0.68, S E=0.45, z=-1.52, P=0.13)$ or English $(\beta=0.49, \mathrm{SE}=.40, z=$ 1.23, $P=0.22)$ considered separately. The effect of language in the conventional $(z=-1.11, p$ $=0.27)$ and unconventional $(z=1.02, p=0.31)$ conditions were not significant either. Regarding RTs, a significant main effect of language $(F(1,20.89)=7.82, P=0.01)$ showed that Chinese-English bilinguals were slower responding to English stimuli $(\beta=1043, S E=$ 60) than Chinese stimuli $(\beta=880, S E=46$; see Fig. 4B). The effect of conventionality was just significant $(F(1,66.96)=3.88, P=0.05)$, bilinguals being slower responding to unconventional $(\beta=972, S E=45)$ than conventional stimuli $(\beta=951, S E=45)$. However, we found no interaction between language and conventionality on $R T(F(1,39.07)=$

$300 \mathbf{1 . 5 7}, \boldsymbol{P}=\mathbf{0 . 2 2})$. Amplitude analysis revealed no main effect of conventionality $(\boldsymbol{F}(\mathbf{1}, \mathbf{1 8})=$ 0.75, $\left.P=\mathbf{0 . 4}, \boldsymbol{\eta}^{2}=\mathbf{0 . 0 4}\right)$ or language $\left(\boldsymbol{F}(\mathbf{1}, \mathbf{1 8})=\mathbf{1 . 9 4}, \boldsymbol{P}=\mathbf{0 . 1 8}, \boldsymbol{\eta}_{p}{ }_{p}=\mathbf{0 . 1}\right)$ on $\mathrm{N} 400$ amplitude and no interaction $\left(\boldsymbol{F}(\mathbf{1}, \mathbf{1 8})=\mathbf{1 . 8 7}, \boldsymbol{P}=\mathbf{0 . 1 9}, \boldsymbol{\eta}^{2}{ }_{p}=\mathbf{0 . 0 9}\right.$; Fig. 6). 
As was the case in the bilingual group, English participants' accuracy was at ceiling in the one-day gap condition. Analysis comparing the Chinese-English bilinguals in English with the native English controls revealed no main effect of conventionality $\left(\chi^{2}{ }_{1}=\mathbf{1}, \boldsymbol{P}=\mathbf{0 . 3 2}\right)$ or group $\left(\chi^{2}{ }_{1}=\mathbf{2 . 9 2}, \boldsymbol{P}=\mathbf{0 . 0 9}\right)$ on accuracy and no interaction $\left(\chi^{2}{ }_{1}=\mathbf{0 . 2 4}, \boldsymbol{P}=\mathbf{0 . 6 2}\right)$. As regards RTs, a main effect of group $(F(1,35.01)=6.29, P=0.02)$ showed that Chinese-English bilinguals were slower responding to English stimuli $(\beta=1051, S E=66)$ than their English native peers $(\beta=888, S E=56)$. There was no significant main effect of conventionality ( $F$ $(1,6.73)=0.59, P=0.47)$ and no interaction $(F(1,8.29)=1.84, P=0.21)$. Amplitude analysis only revealed a significant main effect of $\operatorname{group}\left(F(1,34)=6.75, P=0.01, \eta_{p}^{2}=\right.$

$3120.17)$ on N400 amplitude. No significant main effect of conventionality $(\boldsymbol{F}(\mathbf{1}, \mathbf{3 4})=\mathbf{0 . 0 2}, \boldsymbol{P}$

$\left.313=0.88, \eta_{p}^{2}<0.01\right)$ or no interaction $\left(F(1,34)=0.6, P=0.45, \eta_{p}^{2}=0.02\right.$; Fig. 6) was detected.

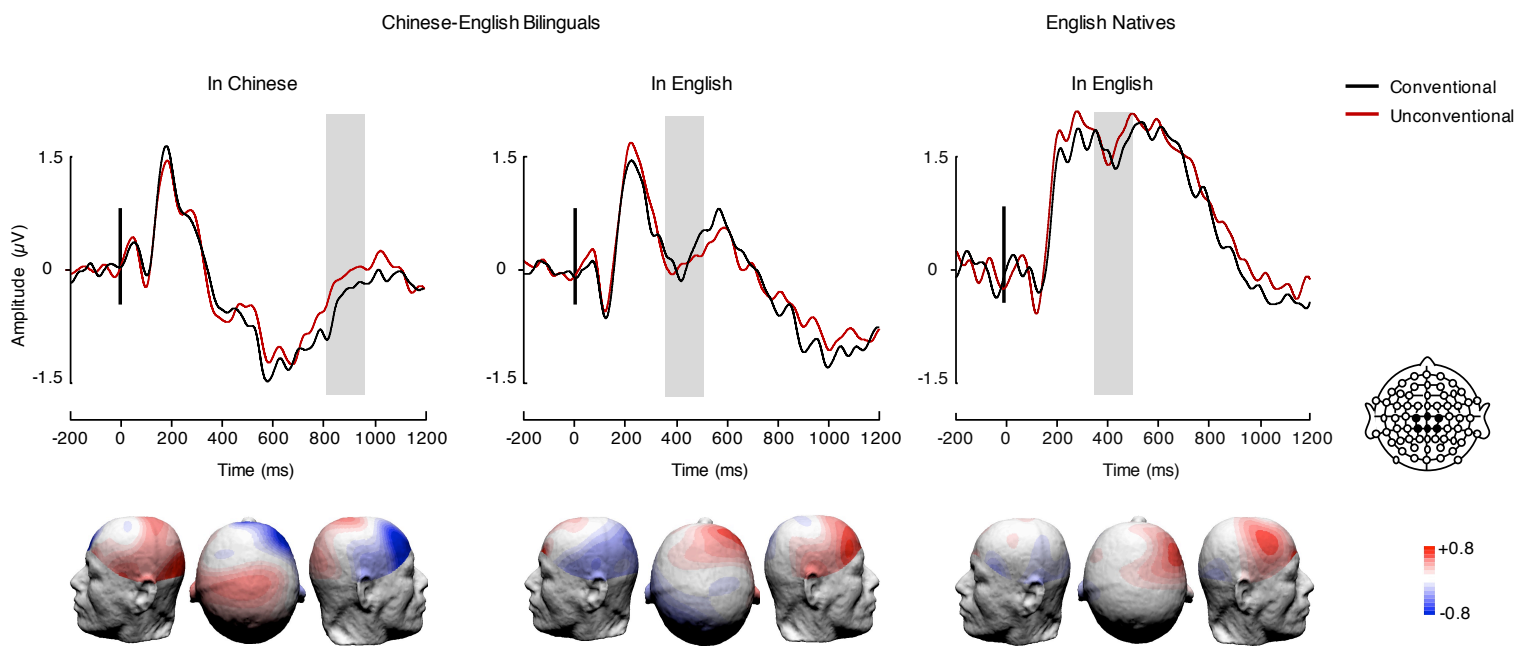

Figure 6. Event-related brain potentials elicited in experiment 1. ERPs depict the linear derivation of 6 electrodes (C1, Cz, C2, CP1, CPz, CP2). Topographical maps show ERP activity across the 64-channel array in the following predictively determined time windows: 813-963 ms after Chinese stimulus onset and between 350-500 $\mathrm{ms}$ after English stimulus onset. Topographies depict differences between unconventional and conventional conditions in all cases.

\section{Replication of the spatiotemporal metaphor effect with year stimuli}

316 In experiment 2, as was the case for days, Chinese-English bilinguals were at ceiling in the interval calculation task with two-year gap stimuli in both the congruent and the incongruent conditions and in both their languages (Fig. 7A). Results revealed no significant main effect of language (Chinese, English; $\chi^{2}{ }_{1}=\mathbf{0 . 3 3}, \boldsymbol{P}=\mathbf{0 . 5 7}$ ) or congruency (congruent, incongruent; $\left.\chi^{2}{ }_{1}=\mathbf{2 . 5 5}, \boldsymbol{P}=\mathbf{0 . 1 1}\right)$ on accuracy and no interaction $\left(\chi^{2}{ }_{1}=\mathbf{0 . 2 1}, \boldsymbol{P}=\mathbf{0 . 6 4}\right)$. We found no effect of language of operation $(F(1,2.61)<0.01, P=0.98)$ or congruency $(F(1,2.1)=0.41$, $\boldsymbol{P}=\mathbf{0 . 5 9})$ on RTs and no interaction $(\boldsymbol{F}(\mathbf{1}, \mathbf{2 . 2 9})=\mathbf{0 . 2 6}, \boldsymbol{P}=\mathbf{0 . 6 6})$. 

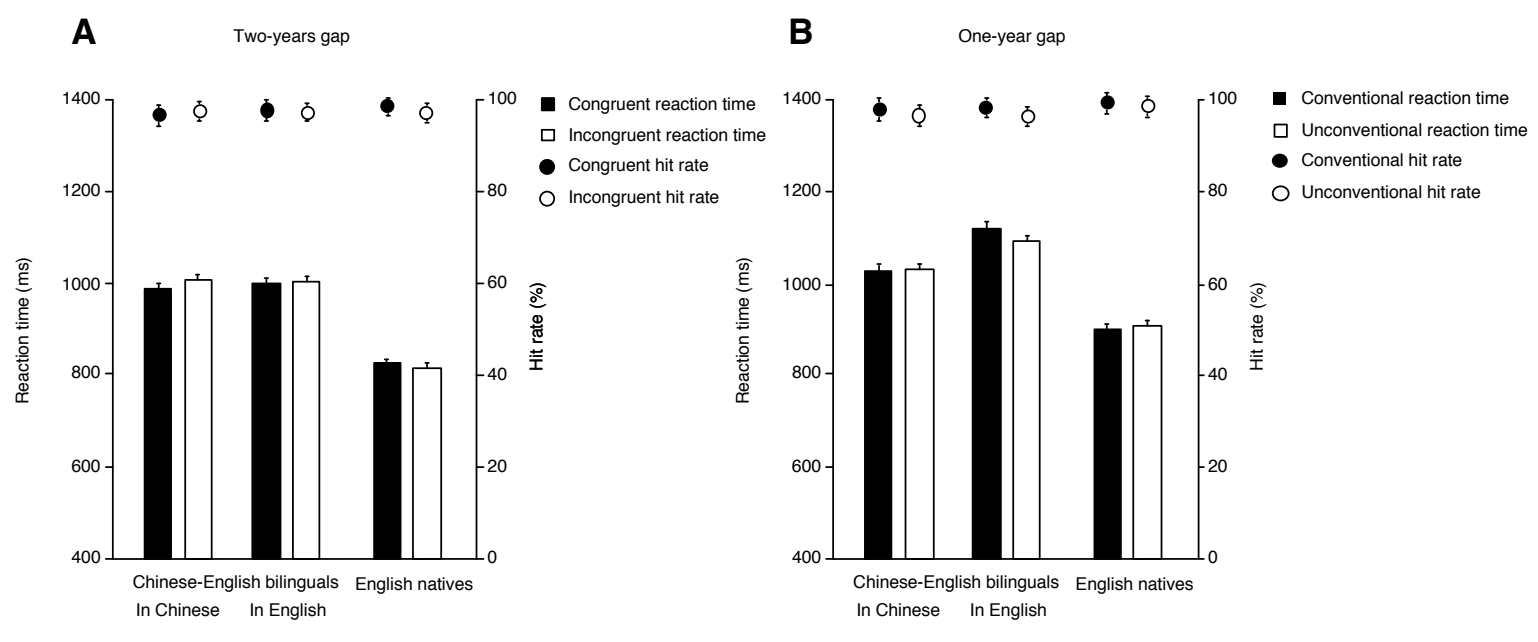

Figure 7. Behavioural results. (A) Two-years gap. (B) One-year gap. Bars represent reaction times and bullets represent accuracy. Error bars depict s.e.m.

323 The within-subject repeated measures ANOVA of ERP data revealed a main effect of

324 congruency on mean N400 amplitude in bilingual participants $\left(F(1,18)=6.96, P=0.02, \eta_{p}^{2}\right.$

$325=0.28)$ and a significant interaction between congruency and language $(F(1,18)=4.6, P=$

$\left.3260.05, \eta_{p}^{2}=0.2\right)$. The main effect of language was not significant $(F(1,18)=0.04, P=0.85$,

$327 \boldsymbol{\eta}_{p}^{2}<\mathbf{0 . 0 1}$ ). Replicating the pattern found for 2-day gap calculations, planned comparisons

328 showed that N400 amplitude was significantly greater for incongruent than congruent

329 stimulus configurations when bilinguals operated in English $(t(18)=3.89, P<0.001$; Fig. 8)

330 but not when they operated in Chinese $(t(18)=0.31, P=0.38)$.

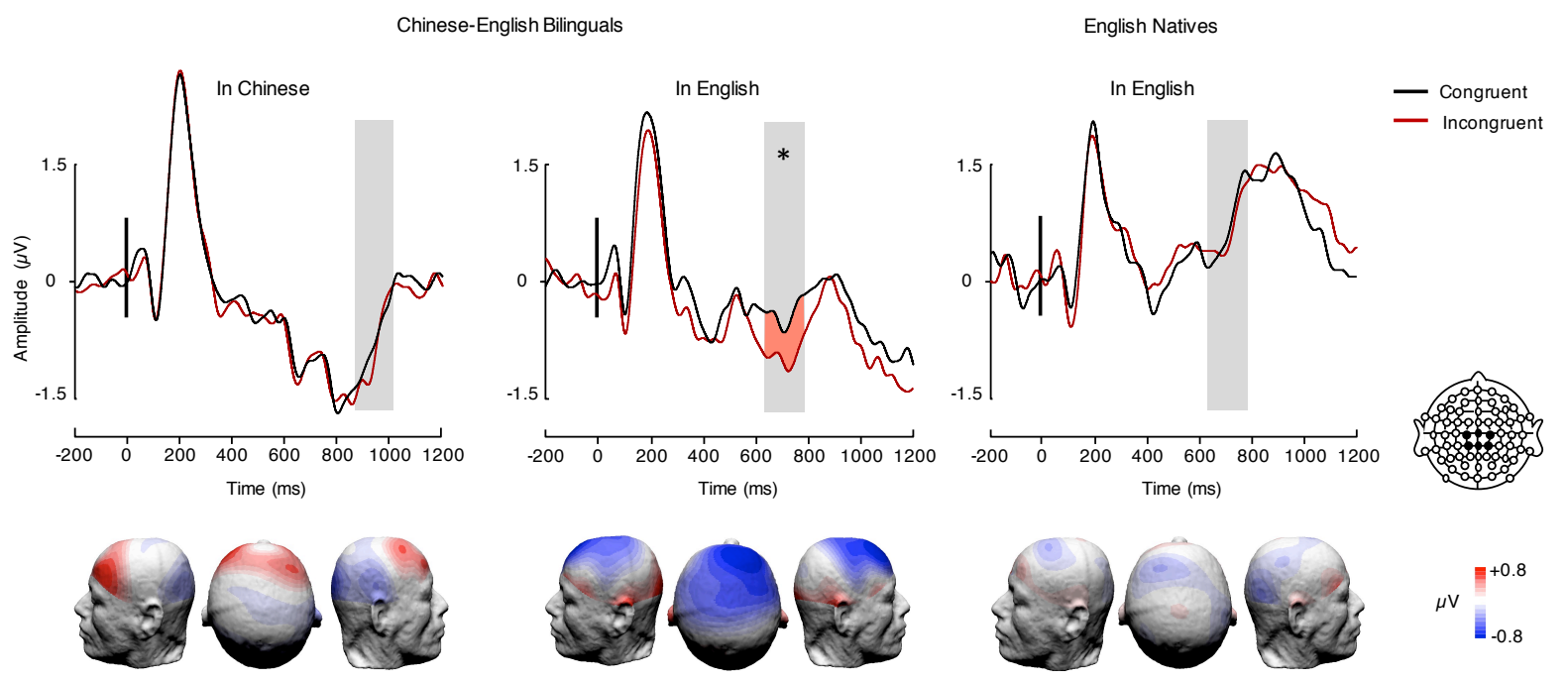

Figure 8. Event-related potentials elicited in experiment 2. ERPs depict the linear derivation of 6 electrodes (C1, Cz, C2, CP1, CPz, CP2). Topographical maps show ERP activity across the 64-channel array between 869-1019 $\mathrm{ms}$ after Chinese stimulus onset and 630-780 ms after English stimulus onset. The predicted time-window of the N400 for Chinese stimuli was between 869-1019 ms after stimulus onset, given that the er-ling - 'twenty' portion 
of the auditory stream lasted for $519 \mathrm{~ms}$. In the case of English stimuli, the N400 time analysis window was 630$780 \mathrm{~ms}$ (since 'twenty' lasted $280 \mathrm{~ms}$ ). Topographies depict differences between incongruent and congruent conditions in all cases.

331 As in Experiment 1, we sought to further characterise the congruency effect found for the

332 English condition in bilinguals by comparing their results with that of native English 333 speakers. English participants' accuracy was at ceiling. No significant main effects (group: $334 \chi^{2}{ }_{1}=\mathbf{0 . 1 2}, P=\mathbf{0 . 7 3}$; congruency: $\chi^{2}{ }_{1}=\mathbf{1 . 5 9}, P=\mathbf{0 . 2 1}$ ) or interaction between congruency 335 and group $\left(\chi^{2}{ }_{1}=\mathbf{0 . 2 4}, \boldsymbol{P}=\mathbf{0 . 6 2}\right)$ was detected. Regarding RTs, Chinese-English bilinguals 336 operating in English were significantly slower $(\beta=1002, S E=74)$ than English native participants $(\beta=819, S E=61)$, as shown by a main effect of group $(F(1,28.13)=6.96, P=$

338 0.01). No significant main effect of congruency $(F(1,2.23)=0.3, P=0.64)$ or interaction $(F(1,1.84)=0.12, P=0.76)$ was detected

340 A between-subject repeated measures ANOVA on N400 mean amplitudes showed a significant main effect of group $\left(F(1,34)=4.13, P=0.05, \eta_{p}^{2}=0.11\right)$ and a significant main effect of congruency $\left(F(1,34)=7.21, P=0.01, \eta_{p}^{2}=0.18\right)$. The interaction between group and congruency was also significant $\left(F(1,34)=4.51, P=0.04, \eta_{p}^{2}=0.12\right)$. Planned comparisons showed that incongruent stimulus configurations elicited greater N400 amplitudes than congruent ones in bilingual participants $(t(18)=3.89, P<0.001$; Fig. 8$)$, but not in English controls $(t(16)=0.35, P=0.37)$.

No measurable effect of conventionality in the case of 1-year gaps

As previously, we first compared bilingual participants' performance in English and Chinese using within-subject analyses. No significant main effect of language (Accuracy: $\chi^{2}{ }_{1}=\mathbf{0 . 4 5}$, $P=0.5 ; \mathrm{RT}: F(1,8.07)=\mathbf{2 . 6 9}, P=0.14)$ or conventionality $\left(\right.$ Accuracy: $\chi^{2}{ }_{1}=1.8, P=0.18$; RT: $\boldsymbol{F}(\mathbf{1}, \mathbf{2 . 1 1})=\mathbf{0 . 2 7}, \boldsymbol{P}=\mathbf{0 . 6 5})$ on either accuracy or RT and no interaction were detected (Accuracy: $\left.\chi^{2}{ }_{1}<0.01, P=0.96 ; \mathrm{RT}: F(1,2.69)=0.78, P=0.45\right)$. The analysis conducted on mean N400 amplitude showed no significant main effect (language: $\boldsymbol{F}(\mathbf{1}, \mathbf{1 8})=\mathbf{0 . 1 4}, \boldsymbol{P}=$ $0.71, \eta^{2}=0.01$; conventionality: $\left.F(1,18)=3.44, P=0.08, \eta_{p}^{2}=0.16\right)$ or interaction $(F(1$, 18) $=0.06, P=0.82, \eta_{p}^{2}=0.003 ;$ Fig. 9). 


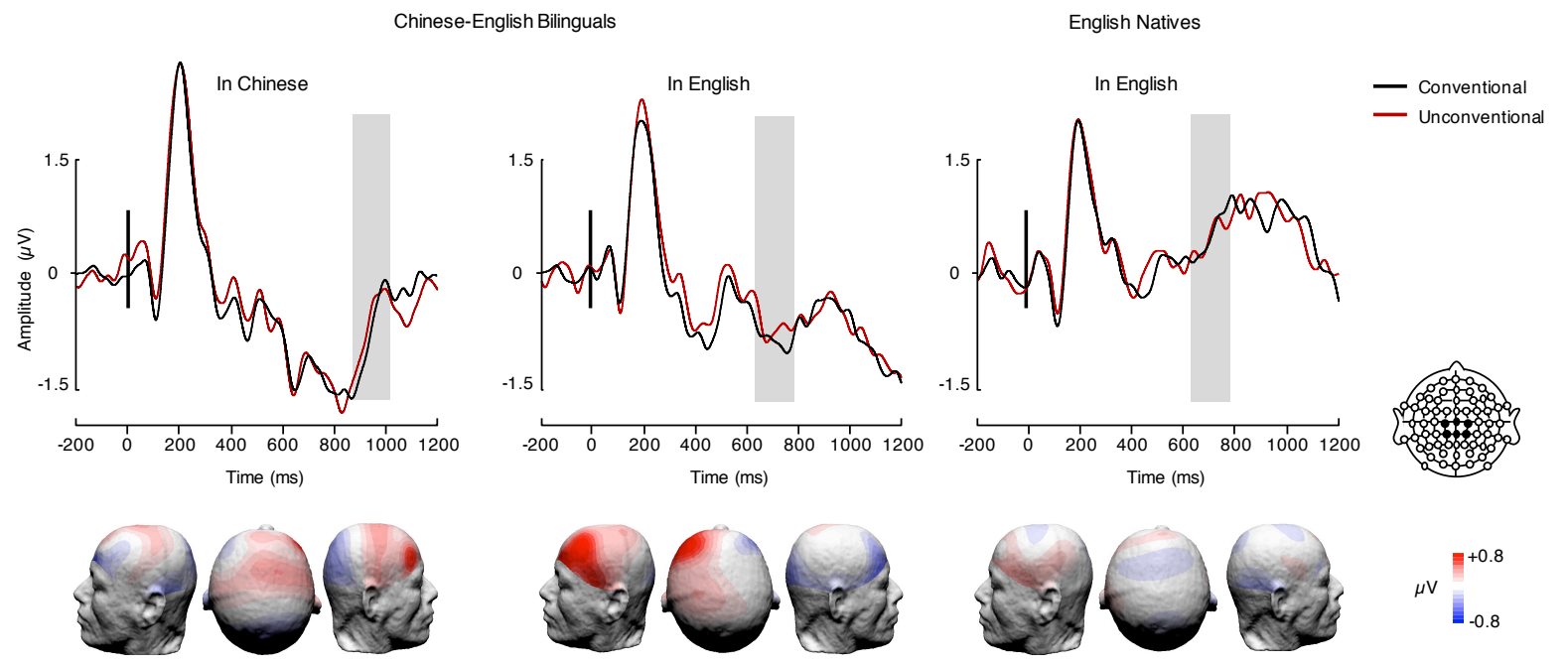

Figure 9. Event-related potentials elicited in experiment 2. ERPs depict the linear derivation of 6 electrodes (C1, Cz, C2, CP1, CPz, CP2). Topographical maps show ERP activity across the 64-channel array between 869-1019 ms after Chinese stimulus onset and 630-780 ms after English stimulus onset. Topographies depict differences between unconventional and conventional conditions in all cases.

356 Finally, we compared Chinese-English bilinguals in English with their English native peers.

357 No significant main effect of group $\left(\chi^{2}{ }_{1}=\mathbf{0 . 0 1}, \boldsymbol{P}=\mathbf{0 . 9 4}\right)$ or conventionality $\left(\chi^{2}{ }_{1}=\mathbf{0 . 0 6}, \boldsymbol{P}\right.$

$358=0.8)$ on accuracy was detected. We found a significant interaction between group and

359 conventionality on accuracy $\left(\chi^{2}{ }_{1}=7.14, P<0.01\right)$. However, post hoc comparisons showed

360 that there was no effect of conventionality in either Chinese-English bilinguals $(\beta=0.46, S E$

$361=0.27, z=1.68, P=0.09)$ or English natives $(\beta=-0.39, S E=0.28, z=-1.43, P=0.15)$. As

362 regards RTs, there was a significant effect of $\operatorname{group}(F(1,32.92)=6.04, P=0.02)$, bilingual

363 participants $(\beta=1109, S E=55)$ being slower responding to English stimuli than English

364 native participants $(\beta=911, S E=58$; Fig. 7B). There was no significant main effect of

365 conventionality $(F(1,1.1)=0.66, P=0.56)$ and no interaction $(F(1,1.67)=0.54, P=$

366 0.55). As regards the ERP analysis, we only found a significant main effect of group on mean

367 N400 amplitude $\left(F(1,34)=4.56, P=0.04, \eta_{p}^{2}=0.12\right.$; Fig. 9). There was no significant

368 main effect of conventionality $\left(F(1,34)=\mathbf{0 . 1 3}, P=\mathbf{0 . 7 3}, \boldsymbol{\eta}^{2}<\mathbf{0 . 0 1}\right)$ and there was no

369 interaction $\left(F(1,34)=0.34, P=0.56, \eta_{p}^{2}=0.01\right)$.

370 In addition, we ran a direct comparison between the congruency effects detected in

371 Experiment 1 and Experiment 2. Paired sample t-test suggested that the difference

372 waves were not statistically different across experiments $(t(18)=0.24, P=0.81)$. A

373 Bayesian paired sample t-test confirmed that the null hypothesis (i.e., no difference in

374 effect magnitude between experiments) was around 4 times more likely than the

$375 \quad$ alternative $\left(\mathrm{BF}_{\mathbf{0 1}}=\mathbf{4 . 1}\right)$. 
377 Here we investigated a potential effect of native spatiotemporal metaphors on time

378 conceptualization in Chinese-English bilinguals operating in their native or their second

379 language. When tested in Chinese, participants did not display congruency effects predicted

380 by spatiotemporal metaphors. Strikingly, however, when they were presented with English

381 stimuli, native language representations interfered with time conceptualization as indicated

382 by more negative N400 amplitudes in the incongruent conditions. Importantly, this pattern of

383 result was mostly replicated using years instead of days as auditory stimuli. In contrast,

384 conventionality effects only appeared as subtle behavioural variations in the case of 1-day

385 intervals and did not entail any N400 amplitude modulation.

386 First, our results are consistent with previous studies that have established unconscious

387 language non-selective access in bilinguals, and particularly Chinese-English bilinguals

388 operating in English (Thierry and $\mathrm{Wu}, 2007$ ). Indeed, and despite recent attempts to provide

389 an alternative account for this mechanism (Costa, Pannunzi, Deco, and Pickering, 2017;

390 Oppenheim, Wu, and Thierry, 2018), Chinese-English bilinguals appear to automatically

391 access Chinese when processing input in English, because otherwise it would be difficult to

392 account for the interference effects observed here. The results thus expand our understanding

393 of language non-selective lexical activation mechanisms in different script bilinguals (Thierry

394 and $\mathrm{Wu}, 2007$; Wu and Thierry, 2010, 2012) by showing unconscious activation of

395 spatiotemporal metaphor representations of Chinese when participants hear English words.

396 Our findings are partly compatible with results from previous behavioural studies suggesting

397 that spatiotemporal metaphors can influence individuals' conceptualization of time

398 (Boroditsky, 2001; Casasanto et al., 2004; Fuhrman et al., 2011; Lai and Boroditsky, 2013;

399 Núñez and Sweetser, 2006, but see Chen, 2007; January and Kako, 2007; Tse and Altarriba,

400 2008). Critically, however, our data establish the locus of interference between language

401 specific expression and time representation at a conceptual level in the absence of

402 participants' awareness, since congruency effects were detected in N400 amplitude

403 modulations rather than behavioural measurements and in conditions where time orientation

404 was irrelevant. Indeed, at debriefing, detailed questioning of the participants revealed no

405 explicit knowledge of hidden manipulations relating to spatiotemporal metaphors. All

406 participants reported having interpreted the task as a simple arithmetic problem, that is,

407 computing an interval of 1 or 2 days, or 1 or 2 years, irrespective of future or past temporal 
reference. Even when directly confronted with the actual construction of the experiment, none of the participants recognised that the future or past reference afforded by the stimuli should conflict with the location of the speakers through which these stimuli were presented, or having resorted consciously to labelling 2-day and 2-year gaps as "front/back-day" or "front/back-year" in Chinese.

It may be considered a surprise, however, that bilingual participants experienced the spatiotemporal metaphor interference effect when performing the task in English rather than Chinese, given that the metaphors belong to Chinese. But this result is in fact compatible with the frequent observation that verbal interference tends to cancel effects of language on conceptualisation (Drivonikou et al., 2007; Gilbert, Regier, Kay, and Ivry, 2006; Roberson and Davidoff, 2000). When stimuli are presented in Chinese, participants suffer withinlanguage competition, such that they cannot verbally recode information because accessing the labels for days and years and engaging in arithmetic computations in Chinese directly compete for selection with metaphoric lexical representations. However, this is arguably not the case when participants operate in English, since no direct within-language competition applies: Metaphors in Chinese can be accessed through cross-language activation. Then, and only then, can interference take place. This mechanistic explanation is consistent with selective interference effects previously shown in bilinguals switching back and forth between their first and second language, whilst making non-verbal decisions on motion events (Athanasopoulos et al., 2015).

In other words, we contend that only when participants heard temporal references in English, they accessed conceptually related expressions specific to their native language. For instance, when a participant tested on a Wednesday heard the English word "Monday", they would have activated qian-tian (literally translated as "front-day"), given that Monday was the day before yesterday relative to the day of testing. This would arguably not have happened when the same participant was tested in the native language Chinese because of the withinlanguage competition effects described above. Alternatively, this would not have happened because days and years in Chinese contain a digit enabling direct gap calculation (with the exception of Sunday). For instance, xing-qi yi - 'Monday' literally translates into "week-1" in English and er-ling $y i$-wu - '2015' literally translates into "two-zero-one-five". Thus, calculating intervals is straightforward in Chinese but not in English, given the previously noted difficulty of bilinguals to compute operation in the second language (Salillas and Wicha, 2012). 
441 As expected, we found a difference between conventional and unconventional control

442 conditions in the case of 1-day gaps in the absence of any metaphorical interference,

443 presumably due to there being no spatiotemporal metaphor for tomorrow and yesterday in

444 either English or Chinese. Indeed, in Chinese, tomorrow is ming-tian (literally, "bright-day”),

445 yesterday is zuo-tian ("past-day"), next year is ming-nian (bright-year), and last year is qu-

446 nian ("gone-year"), thus any effect of orientation for one day/year gaps could only relate to

447 effects of spatial orientation conventions for time. Conventionality had an effect in

448 experiment 1 (days) but not experiment 2 (years). We contend that this was the case because

449 time conventionality effects weaken as the size of time chunks increases, i.e., it is more

450 difficult to conceptualise the year ahead as in front than the day ahead as in front (Hellström

451 and Rammsayer, 2004 ; Lewis and Miall, 2003). Furthermore, conventionality did not affect

452 ERP amplitude as metaphor congruency did. Here the argument would be that interference

453 between convention and time representation does not occur at a semantic level but rather in

454 terms of direct mapping between stimulus and response. Spatiotemporal metaphors rely

455 exclusively on language and thus result in a semantic interference effect to start with (here

456 resulting in a measurable N400 modulation). In other words, spatiotemporal metaphors are

457 resolved at a pre-response, semantic level, whereas conventionality effects do not come into

458 play during semantic access but rather interfere directly with the task at hand (particularly in

459 the case of days).

460 To conclude, the present study provides the first electrophysiological evidence for a deep,

461 unconscious, and pervasive influence of native spatiotemporal metaphors on time

462 conceptualization in bilinguals. These findings not only bridge unconscious language non-

463 selective access in bilinguals with predictions from linguistic relativity theory but also

464 demonstrate the staggering level of interactivity involved. After all, our Chinese-English

465 bilingual participants suffered semantic interference when the English label of the day after

466 tomorrow was played through loudspeakers located in front of them, as compared to when

467 the same label was played in their back. Given that this did not happen when they listened to

468 the label of tomorrow, or any label in Chinese, and that it generalised to year labels, our study

469 demonstrates that abstract concepts such as that of time are highly permeable to linguistic

470 representations specific of the native language even when bilinguals operate in their second

471 language. 


\section{Author contributions}

Y.L. and G.T. conceived the experiment; Y.L. collected the data; Y.L., A.C., and G.T. analysed the data; Y.L., A.C., Y.J.W., and G.T interpreted the data. Y.L. and G.T. wrote the first draft of the paper. Y.L., A.C., Y.J.W., and G.T revised the manuscript until final.

\section{Acknowledgements}

The authors wish to thank E. Devienne for her assistance with data collection and also P. Athanasopoulos, C. Barbet, and M. Jones, and M. Vihman for comments.

\section{All materials used and data collected in this study are available upon request to the corresponding author.}

\section{References}

Athanasopoulos, P., Bylund, E., Montero-Melis, G., Damjanovic, L., Schartner, A., Kibbe, A., et al. 2015. Two Languages, Two Minds: Flexible Cognitive Processing Driven by Language of Operation. Psychol Sci, 26(4), 518-526.

Barr, D. J. 2013. Random effects structure for testing interactions in linear mixed-effects models. Front Psychol, 4, 328-328.

Barr, D. J., Levy, R., Scheepers, C., Tily, H. J. 2013. Random effects structure for confirmatory hypothesis testing: Keep it maximal. Journal of Memory and Language, 68(3), 255-278.

Bates, D., Maechler, M., Dai, B. 2008. lme4: Linear mixed effects models using s4 classes (Version R package version 0.999375-28).

Boroditsky, L. 2001. Does language shape thought?: Mandarin and English speakers' conceptions of time. Cognitive Psychology, 43(1), 1-22.

Boroditsky, L., Fuhrman, O., McCormick, K. 2011. Do English and Mandarin speakers think about time differently? Cognition, 118(1), 123-129.

Casasanto, D., Boroditsky, L., Phillips, W., Greene, J., Goswami, S., Bocanegra-Thiel, S., et al. 2004. How deep are effects of language on thought? Time estimation in speakers of English, Indonesian, Greek, and Spanish. Paper presented at the Proceedings of the Annual Meeting of the Cognitive Science Society.

Chen, J-Y. 2007. Do Chinese and English speakers think about time differently? Failure of replicating Boroditsky (2001). Cognition, 104(2), 427-436.

Costa, A., Pannunzi, M., Deco, G., Pickering, M. J. 2017. Do Bilinguals Automatically Activate Their Native Language When They Are Not Using It? Cogn Sci, 41(6), 1629-1644.

de la Fuente, J., Santiago, J., Román, A., Dumitrache, C., Casasanto, D. 2014. When you think about it, your past is in front of you: how culture shapes spatial conceptions of time. Psychol Sci, 25(9), 1682-1690.

Dijkstra, T., van Heuven, W. J. B. 2002. The Architecture of the Bilingual Word Recognition System: From Identification to Decision. Bilingualism: Language and Cognition, 5, 175-197.

Drivonikou, G. V., Kay, P., Regier, T., Ivry, R. B., Gilbert, A. L., Franklin, A., et al. 2007. Further evidence that Whorfian effects are stronger in the right visual field than the left. Proc Natl Acad Sci USA, 104(3), 10971102.

Fox, J., Weisberg, S. 2014. Package car.

Fuhrman, O., McCormick, K., Chen, E., Jiang, H., Shu, D., Mao, S., et al. 2011. How linguistic and cultural forces shape conceptions of time: English and Mandarin time in 3D. Cogn Sci, 35(7), 1305-1328.

Gilbert, A. L., Regier, T., Kay, P., Ivry, R. B. 2006. Whorf hypothesis is supported in the right visual field but not the left. Proc Natl Acad Sci USA, 103(2), 489-494. 
Gratton, G., Coles, M. G. H., Donchin, E. 1983. A new method for off-line removal of ocular atficat. Electroencephalography and Clinical Neurophysiology, 55(4), 468-484.

Hellström Å Rammsayer T.H. 2004. Effects of time-order, interstimulus interval, and feedback in duration discrimination of noise bursts in the 50- and 1000-ms ranges. Acta Psychologica, 116(1),1-20.

Hoshino, N., Thierry, G. 2012. Do Spanish-English bilinguals have their fingers in two pies-or is it their toes? An electrophysiological investigation of semantic access in bilinguals. Frontiers in psychology, $3,9$.

Jaeger, T. F. 2008. Categorical data analysis: Away from ANOVAs (transformation or not) and towards logit mixed models. Journal of Memory and Language, 59(4), 434-446.

January, D., Kako, E. 2007. Re-evaluating evidence for linguistic relativity: Reply to Boroditsky. Cognition, $104(2), 417-426$

Kutas, M., Hillyard, S. A. 1980. Reading senseless sentences - brain potentials reflect semantic incongruity. Science, 207(4427), 203-205.

Kutas, M., Hillyard, S. A. 1984. Event-related brain potentials (ERPs) elicited by novel stimuli during sentence processing. Annals of the New York Academy of Sciences, 425(Jun), 236-241.

Kutas, M., Lindamood, T., Hillyard, S. 1984. Word expectancy and event-related brain potentials during sentence processing. In S. Kornblum J. Requin (Eds.), Preparatory states and processes (pp. 217 - 237. Hillsdale Lawrence Erlbaum.

Kuznetsova, A., Brockhoff, P. B., Christensen, R. H. B. 2017. lmerTest Package: Tests in Linear Mixed Effects Models. Journal of Statistical Software. 1(13), 12787.

Lai, V. T., Boroditsky, L. 2013. The immediate and chronic influence of spatio-temporal metaphors on the mental representations of time in english, mandarin, and mandarin-english speakers. Front Psychol, 4, 142.

Lee, B.; Meade, G.; Midgley, K.J.; Holcomb, P.J.; Emmorey, K. 2019) ERP Evidence for Co-Activation of English Words during Recognition of American Sign Language Signs. Brain Sci. 9, 148.

Lewis, P.A., Miall, R.C. 2003. Distinct systems for automatic and cognitively controlled time measurement: evidence from neuroimaging. Current Opinion in Neurobiology. 13(2), 250-255.

Lenth, R.V. 2016. lsmeans: Least-Squares Means (Version R package version 2.22.).

Lupyan, G. 2012. Linguistically modulated perception and cognition: the label-feedback hypothesis. Front Psychol, 3, 54.

Meade, G.; Midgley, K.J.; Sevcikova Sehyr, Z.; Holcomb, P.J.; Emmorey, K. 2017. Implicit co-activation of American Sign Language in deaf readers: An ERP study. Brain Lang. 170, 50-61.

Núñez, R. E., Sweetser, E. 2006. With the future behind them: convergent evidence from aymara language and gesture in the crosslinguistic comparison of spatial construals of time. Cogn Sci, 30(3), 401-450.

Oppenheim, G., Wu, Y. J., Thierry, G. 2018. Found in translation: Late bilinguals do automatically activate their native language when they are not using it. Cogn Sci, 42: 1700-1713.

R Core Team. 2012. R: A language and environment for statistical computing. R Foundation for Statistical Computing. Vienna, Austria.

Roberson, D., Davidoff, J. 2000. The categorical perception of colors and facial expressions: The effect of verbal interference. Memory Cognition, 28(6), 977-986.

Salillas, E., Wicha, N. Y. Y. 2012. Early Learning Shapes the Memory Networks for Arithmetic: Evidence From Brain Potentials in Bilinguals. Psychol Sci, 23(7), 745-755.

Slobin, D. 1996. From 'thought and language' to 'thinking for speaking'. In J. Gumperz S. Levinson (Eds.), Rethinking linguistic relativity (pp. 70-96). Cambridge: Cambridge University Press.

Thierry, G. 2016. Neurolinguistic Relativity: How Language Flexes Human Perception and Cognition. Lang Learn, 66(3), 690-713.

Thierry, G., Wu, Y. J. 2004. Electrophysiological evidence for language interference in late bilinguals. NeuroReport, 15(10), 1555-1558.

Thierry, G., Wu, Y. J. 2007. Brain potentials reveal unconscious translation during foreign-language comprehension. Proc Natl Acad Sci USA, 104(30), 12530-12535.

Tse, C-S., Altarriba, J. 2014. Evidence against linguistic relativity in Chinese and English: A case study of spatial and temporal metaphors. Journal of Cognition and Culture, 8(3-4), 335-357. 
van Heuven, W. J. B., Dijkstra, T. 2010. Language comprehension in the bilingual brain: fMRI and ERP support for psycholinguistic models. Brain Research Reviews, 64(1), 104-122.

van Heuven, W. J. B., Dijkstra, T., Grainger, J. 1998. Orthographic neighborhood effects in bilingual word recognition. Journal of Memory and Language, 39(3), 458-483.

Wen, Y., Filik, R. and van Heuven, W.J.B 2018. Electrophysiological dynamics of Chinese phonology during visual word recognition in Chinese-English bilinguals Scientific Reports. 6869.

Whorf, B. 1956. Language, thought, and reality. Cambridge, MA: MIT Press.

Wu, Y. J., Thierry, G. 2010. Chinese-English Bilinguals Reading English Hear Chinese. Journal of Neuroscience, 30(22), 7646-7651.

Wu, Y. J., Thierry, G. 2012. Unconscious translation during incidental foreign language processing. Neuroimage, 59(4), 3468-3473. 
${ }^{\star}$ Data and Code Availability Statement

All materials used and data collected in this study are available upon request to the corresponding author. 